\section{International Scientific Journal Theoretical \& Applied Science}

p-ISSN: 2308-4944 (print) $\quad$ e-ISSN: 2409-0085 (online)

Year: $2016 \quad$ Issue: 7 Volume: 39

Published: $30.07 .2016 \quad \underline{\text { http://T-Science.org }}$

SECTION 9. Chemistry and chemical technology.
Lala Rafiq Mahmudova

Researcher, National Academy of Sciences of Azerbaijan Academician A.M.Guliyev Institute of Chemistry of Additives

Lalamahmudova81@ mail.ru

Mirze Mammad Movsumzadeh Deputy director of National Academy of Sciences of Azerbaijan Academician A.M.Guliyev Institute of Chemistry of Additives, professor

Idris Mejid Akhmedov

Leader researcher, National Academy of Sciences of Azerbaijan Academician A.M.Guliyev Institute of Chemistry of Additives idrismecid@yahoo.com

Nusrat Abbas Aliyev

Leader researcher, National Academy of Sciences of Azerbaijan Academician A.M.Guliyev Institute of Chemistry of Additives

Malakhat Talat Abbasova

Leader researcher, National Academy of Sciences of Azerbaijan Academician A.M.Guliyev Institute of Chemistry of Additives

Natavan Rasul Sultanova

Leader researcher, National Academy of Sciences of Azerbaijan Academician A.M.Guliyev Institute of Chemistry of Additives

Irada Malik Eyvazova

Leader researcher, National Academy of Sciences of Azerbaijan Academician A.M.Guliyev Institute of Chemistry of Additives irada.eyvazova@gmail.com

\title{
DEVELOPING BIOSTABLE FUEL COMPOSITIONS BASED ON DIESEL FUELS AND BIODIESELS
}

\footnotetext{
Abstract: In the article there have been indicated the results of microbiological studies of biodiesel produced by transesterification of vegetable oils with the use of nano $\mathrm{CaO}$ catalyst, and its $7 \%$ fuel composition with oil diesel fuel. It has been established that both the biodiesel and its $7 \%$ fuel composition are not biologically stalev and fully affected by bacteria and fungi. There are shown results of the tests $\alpha$-phenyl- $\beta$-nitroethene as a biocide to protect the biodiesel and its fuel compositions from bio-deterioration.

Key words: alternative fuel, biodiesel, microbial damage, biological stability, microbial protection, biocide, $\alpha-$ phenyl- $\beta$-nitroethane.

Language: Russian

Citation: Mahmudova LR, Movsumzadeh MM, Akhmedov IM, Aliyev NA, Abbasova MT, Sultanova NR, Eyvazova IM (2016) DEVELOPING BIOSTABLE FUEL COMPOSITIONS BASED ON DIESEL FUELS AND BIODIESELS. ISJ Theoretical \& Applied Science, 07 (39): 70-74.

Soi: http://s-o-i.org/1.1/TAS-07-39-12 Doi: crossef http://dx.doi.org/10.15863/TAS.2016.07.39.12

\section{РАЗРАБОТКА БИОСТОЙКИХ ТОПЛИВНЫХ КОМПОЗИЦИЙ НА ОСНОВЕ ДИЗЕЛЬНЫХ ТОПЛИВ И БИОДИЗЕЛЕЙ}

Аннотация: В статье приведень результаты микробиологических исследований биодизеля, полученного трансэтерификацией растительных масел с применением нано СаО катализатора, а также его 7\%-ной топливной композиции с нефтянымм дизельным топливом. Установлено, что как биодизель, так и его 7\%-ная топливная композищия, не биостойки и полностью поражаются бактериями и грибами. Приведены результаты испытаний $\alpha$-фенил- $\beta$-нитроэтена в качестве биоцида для защить биодизеля и его топливной композиции от биоповреждения.
} 


\begin{tabular}{|c|c|c|c|c|c|c|}
\hline Impact Factor: & $\begin{array}{l}\text { ISRA (India) } \\
\text { ISI (Dubai, UAE } \\
\text { GIF (Australia) } \\
\text { JIF }\end{array}$ & $\begin{array}{r}=1.344 \\
=0.829 \\
=0.564 \\
=1.500\end{array}$ & $\begin{array}{l}\text { SIS (USA) } \\
\text { PUHЦ (Russia) } \\
\text { ESJI (KZ) } \\
\text { SJIF (Morocco) }\end{array}$ & $\begin{array}{l}=0.912 \\
=0.234 \\
=1.042 \\
=\mathbf{2 . 0 3 1}\end{array}$ & $\begin{array}{l}\text { ICV (Poland) } \\
\text { PIF (India) } \\
\text { IBI (India) }\end{array}$ & $\begin{array}{l}=6.630 \\
=1.940 \\
=4.260\end{array}$ \\
\hline
\end{tabular}

Ключевые слова: альтернативное топливо, биодизель, микробиологическое поражение, биостойкость, микробиологическая защита, биоцид, $\quad \alpha$-фенил- $\beta$-нитроэтен.

Истощение запасов сырой нефти, и резкий рост грузоподъемных автомобилей обусловили необходимость получения топлив из альтернативного нефти сырья. В настоящее время проводятся всесторонние исследования, направленные на создание новых видов топлива с экологически безопасными и высокими эксплуатационными свойствами. Одним из распространенных способов является использование в качестве сырья растительных масел [1-4].

Получение дизельных топлив (биодизеля) из растительных масел осуществляется реакцией трансэтерификации растительных масел со спиртами (метиловым, этиловым и др.) В качестве катализаторов используют гомогенные и гетерогенные катализаторы: щелочные металлы $(\mathrm{Na}, \mathrm{K}, \mathrm{Li})$, щелочи $(\mathrm{NaOH}, \mathrm{KOH}, \mathrm{LiOH})$, разные соли $\left(\mathrm{K}_{2} \mathrm{CO}_{3}, \mathrm{Na}_{2} \mathrm{CO}_{3}, \mathrm{KNO}_{3}\right)$, осажденные на $\gamma$ $\mathrm{Al}_{2} \mathrm{O}_{3}$, гетерогенные катализаторы типа КУ - 2, Амберлит - 15, А-26 и А-28 [5-7].

Нами разработан высокоэффективный катализатор - нано частицы $\mathrm{CaO}$ с размерами зернышек 5-10 нанометров [8, 9].

Трансэтерификацией подсолнечного масла метиловым или этиловым спиртами с использованием указанного катализатора нами с выходом 90\% синтезирован биодизель, структура которого подтверждена данными ИК- и ПМРспектроскопии.

Характеристика биодизелей, полученных трансэтерификацией подсолнечного, кукурузного и хлопкового масел метиловым и этиловым спиртами с использованием нано $\mathrm{CaO}$ катализатора приведена в таблица 1.

Основные характеристики эфиров на основе растительных масел.

Таблица 1

\begin{tabular}{|c|c|c|c|c|c|c|c|}
\hline \multirow[t]{3}{*}{ Показатели } & \multirow{3}{*}{$\begin{array}{c}\text { Диз. } \\
\text { топливо }\end{array}$} & \multicolumn{6}{|c|}{ Эфиры растительных масел } \\
\hline & & \multicolumn{2}{|c|}{ Подсолнечного масла } & \multicolumn{2}{|c|}{ Кукурузного масла } & \multicolumn{2}{|c|}{ Хлопкового масла } \\
\hline & & Метил & Этил & Метил & Этил & Метил & Этил \\
\hline $\begin{array}{l}\text { Плотность } \\
20^{0} \mathrm{C}, d_{4}^{20}, \text { кг/м } 3\end{array}$ & 0,796 & 0,8812 & 0,8813 & 0,8660 & 0,8767 & 0,8720 & 0.8670 \\
\hline $\begin{array}{l}\text { Кинемат. вязкость } \\
\text { при } 20^{\circ} \mathrm{C}, v \quad \mathrm{Mм}^{2} / \mathrm{c}\end{array}$ & 3,92 & 8,6 & 9,5 & 7,6 & 7,8 & 7,4 & 7,5 \\
\hline $\begin{array}{l}\text { Температура } \\
\text { кипения, } T_{\kappa}{ }^{0} C\end{array}$ & - & $\begin{array}{l}172-180^{0} \\
(2 \mathrm{MM})\end{array}$ & $\begin{array}{c}180-192^{0} \\
(2 \mathrm{MM})\end{array}$ & $\begin{array}{l}170-176^{0} \\
(0,5 \mathrm{MM})\end{array}$ & $\begin{array}{l}190-194^{0} \\
(0,5 \mathrm{MM})\end{array}$ & $\begin{array}{l}188-190^{0} \\
(2,5 \mathrm{MM})\end{array}$ & $\begin{array}{r}195-198^{0} \\
(0,5 \mathrm{MM})\end{array}$ \\
\hline $\begin{array}{l}\text { Показатель } \\
\text { преломления, } n_{D}^{20}\end{array}$ & 1,4694 & 1,4539 & 1,4536 & 1,4540 & 1,4522 & 1,4502 & 1,4514 \\
\hline Цетановое число & 3 & 48 & 49 & 47 & 46 & 46 & 46 \\
\hline Биостойкость & & & & е биостой & & & \\
\hline
\end{tabular}

Известно, что биодизель используют в виде $5-10 \%$ добавок к дизельному топливу. В ближайшем будущем, с целью создания дополнительных сырьевых ресурсов для производства дизельных топлив, предполагается повысить содержание биодизеля до $20 \%$.

Нами исследовано влияние синтезированных биодизелей на основные эксплуатационные свойства дизельного топлива, выпускаемого
Бакинским
Нефтеперерабатывающим Заводом им.Г.Алиева [10]. Испытанием 5, 10, 15 и $20 \%$-ной композиции биодизелей с дизельном топливом установлено, что по мере увеличения процентного содержания биодизеля в композиции противоизносные свойства улучшаются от 0,52-0,54 мм до 0,45-0,48 мм, при этом само дизельное топливо (ГОСТ 305-82) имеет диаметр пятна износа 0,68 мм (таб.2). 


\begin{tabular}{|c|c|c|c|c|c|c|}
\hline Impact Factor: & $\begin{array}{l}\text { ISRA (India) } \\
\text { ISI (Dubai, UAE } \\
\text { GIF (Australia) } \\
\text { JIF }\end{array}$ & $\begin{array}{l}=1.344 \\
=0.829 \\
=0.564 \\
=1.500\end{array}$ & $\begin{array}{l}\text { SIS (USA) } \\
\text { PИНЦ (Russia) } \\
\text { ESJI (KZ) } \\
\text { SJIF (Morocco) }\end{array}$ & $\begin{array}{l}=0.912 \\
=0.234 \\
=1.042 \\
=2.031\end{array}$ & $\begin{array}{l}\text { ICV (Poland) } \\
\text { PIF (India) } \\
\text { IBI (India) }\end{array}$ & $\begin{array}{l}=6.630 \\
=1.940 \\
=4.260\end{array}$ \\
\hline
\end{tabular}

Таблица 2

Результаты испытаний противоизносной эффективности композиций.

\begin{tabular}{|c|c|}
\hline Название композиции & Диаметр пятна износа, мм \\
\hline Дизтопливо (ГОСТ 305 - 82) & 0,68 \\
\hline Дизтопливо + 5 \% биоди зеля & $0,52-0,54$ \\
\hline Дизтопливо + $10 \%$ биодизеля & 0,50 \\
\hline Дизтопливо + $15 \%$ биодизеля & 0,50 \\
\hline Дизтопливо + 20 \% биодизеля & $0,45-0,48$ \\
\hline
\end{tabular}

В результате испытаний было также установлено, что добавление в дизельное топливо $0,1 \%$ биодизеля обеспечивает высокую антикоррозионную защиту металла (98\%). Дальнейшее добавление биодизеля $(0,5-5,0 \%)$ обеспечивает полную защиту - металл совершенно не подвергается коррозии [11].

При изучении влияния биодизеля на цетановое число топливной композиции установлено, что введение в состав нефтяного дизельного топлива синтезированного нами биодизеля увеличивает цетановое число от 43 до 48 единиц. [12].

Таким образом, добавление биодизеля к нефтяным дизельным топливам улучшает их противоизносные и антикоррозионные свойства, увеличивает цетановое число.

Основным недостатком биодизеля является ограниченный срок его хранения (не более 3 месяцев). По-видимому, это объясняется легкой поражаемостью биодизеля микроорганизмами.

В данной работе нами проведены микробиологические исследования по биостойкости биодизеля и его $7 \%$-ной композиции с нефтяным дизельным топливом, а также рассмотрена возможность продления срока их хранения путем применения биоцидов (таб.3). Определение биостойкости биодизеля и его 7\%ной композиции с дизельным топливом проводили по ГОСТ 9023-74 «Единая система защиты от коррозии и старения. Топлива нефтяные. Метод лабораторных испытаний биостойкости топлив, защищенных противомикробными присадками». Сущность метода заключается в инкубации топлив с присадкой или без нее в контакте с водноминеральной средой, зараженной специально подобранными микроорганизмами, наиболее активно развивающимися за счет данного топлива без присадки.

Для испытаний использовали чистые культуры гриба Cladosporium resinae и бактерии Pseudomonas aeruginosa. Инкубацию образцов проводили в термостате в условиях, оптимальных для развития микроорганизмов (температура $29 \pm 22^{\circ} \mathrm{C}, \quad$ влажность 90\%). Результаты исследования приведены в табл.3.

Результаты микробиологических испытаний.

Таблица 3

\begin{tabular}{|c|c|c|c|c|}
\hline \multirow[t]{2}{*}{ № } & \multirow[t]{2}{*}{ Образец } & \multirow[t]{2}{*}{$\begin{array}{c}\text { Концентрация } \\
\text { биоцида, \% }\end{array}$} & \multicolumn{2}{|c|}{$\begin{array}{c}\text { Диаметр угнетения роста микроорганизмов, } \\
\text { см }\end{array}$} \\
\hline & & & бактерии & грибы \\
\hline 1 & Биодизель & - & + & + \\
\hline & $\begin{array}{l}\text { Композиция } 1 \text { (7\% биодизеля }+ \\
93 \% \text { нефтяного дизельного } \\
\text { топлива) }\end{array}$ & - & + & + \\
\hline 3 & $\begin{array}{l}\text { Биодизель } \\
\text { нитроэтен }\end{array}$ & 0.25 & 1.6 & 2.8 \\
\hline & $\begin{array}{l}\begin{array}{l}\text { Композиция } \\
\text { нитроэтен }\end{array} \\
\end{array}$ & 0.1 & 2.0 & $\begin{array}{c}\text { Слабый рост } \\
\text { микроорганизмов }\end{array}$ \\
\hline
\end{tabular}




\begin{tabular}{|l|l|c|c|c|}
\hline & & 0.3 & 2.3 & 3.0 \\
\cline { 3 - 5 } & & 0.5 & 3.0 & 3.5 \\
\hline & Композиция 1+8-оксихинолин & 0.5 & 1.3 & + \\
\hline
\end{tabular}

«+» - обильный рост микроорганизмов

В результате испытаний установлено, что у биодизеля и его 7\%-ной композиции с дизельным топливом совершенно отсутствует биостойкость и в течение суток, в условиях испытаний, оба полностью поражаются микроорганизмами.

Известно, что нефтяные дизельные топлива при хранении в неблагоприятных условиях (повышенная температура и влажность) также поражаются микроорганизмами. Используя углеводороды топлив в качестве источника углерода, микроорганизмы ухудшают его качество и в итоге делают негодными для использования.

Степень микробиологического поражения зависит от углеводородного состава топлив.

Биотоплива, содержащие сложноэфирную группу и ненасышенные связи, должны еще активнее подвергаться микробиологическому поражению, что подтверждено данными наших испытаний.

Известно, что наиболее эффективным методом защиты от микробиологического поражения является применение антимикробных присадок - биоцидов. Анализ патентной и периодической литературы показывает разнообразие химических соединений, предложенных в качестве биоцидов для топлив. Среди них производные имидазолина, октиламинотиазол, четвертичные аммониевые основания, монометиловый эфир диэтиленгликоля, 2-метоксиэтанол и т.д.

Исходя из доступности и высокой антимикробной активности нами в качестве биоцида к биодизелю и его 7\%-ной композиции исследован $\alpha$-фенил- $\beta$-нитроэтен, синтезированный нами из бензальдегида и нитрометана по известной методике [13] и исследованный нами ранее в составе смазочных масел [14].

В качестве эталона использован 8оксихинолин, известный в литературе как биоцид для топлив и масел [15].

Микробиологические испытания, проведенные по приведенному выше ГОСТ показали, что 0,3\%-ная добавка к биодизелю $\alpha$ фенил- $\beta$-нитроэтена обеспечивает ее длительную биостойкость к поражению микроорганизмами (бактериями и грибами).

Для защиты 7\%-ной композицию биотоплива с дизельным топливом были исследованы составы, содержащие 0,$1 ; 0,3 ; 0,5 \%$ добавки биоцида - $\alpha$-фенил- $\beta$-нитроэтена.

Результаты исследований, представленные в таблице 3 , свидетельствуют о том, что введение в состав топливной композиции $\alpha$-фенил- $\beta$ нитроэтена в концентрации $0,1-0,5 \%$ для бактерии и $0,3-0,5 \%$ для грибов полностью подавляет рост бактерий и грибов соответственно.

На протяжении всего эксперимента топливная композиция приобретает биостойкость, которая сохраняется даже в условиях принудительного заражения микроорганизмами.

Исследования показали, что для продления срока хранения биодизеля, а также его 7\%-ной композиции с дизельным топливом необходимо добавление в их состав $0,3-0,5 \% \quad \alpha$-фенил- $\beta$ нитроэтена, который следует вводить в состав биодизеля сразу после его получения или на стадии приготовления его композиции с дизельным топливом.

Всесторонние исследования показали, что введение в состав топливной композиции 7\%ного биодизеля с дизельным топливом $\alpha$-фенил$\beta$-нитроэтена в концентрациях $0,1-0,5 \%$ не ухудшает основные физико-химические и эксплуатационные свойства этой композиции.

Таким образом, нами разработана биостойкая топливная композиция на основе альтернативного топлива - биодизеля и нефтяного дизельного топлива, обладающая помимо высоких противоизносных и антикоррозионных свойств, также и повышенным цетановым числом.

\section{References:}




\begin{tabular}{|c|c|c|c|c|c|c|}
\hline Impact Factor: & $\begin{array}{l}\text { ISRA (India) } \\
\text { ISI (Dubai, UAF } \\
\text { GIF (Australia) } \\
\text { JIF }\end{array}$ & $\begin{array}{l}=1.344 \\
=0.829 \\
=0.564 \\
=1.500\end{array}$ & $\begin{array}{l}\text { SIS (USA) } \\
\text { PИНЦ (Russia } \\
\text { ESJI (KZ) } \\
\text { SJIF (Morocco }\end{array}$ & $\begin{array}{l}=\mathbf{0 . 9 1 2} \\
=\mathbf{0 . 2 3 4} \\
=\mathbf{1 . 0 4 2} \\
=\mathbf{2 . 0 3 1}\end{array}$ & $\begin{array}{l}\text { ICV (Poland) } \\
\text { PIF (India) } \\
\text { IBI (India) }\end{array}$ & $\begin{array}{l}=6.630 \\
=1.940 \\
=4.260\end{array}$ \\
\hline
\end{tabular}

1. Lin CY, Lin HA (2006) Fuel structure and properties of biodizel produced by peroxidation Fuel,v.85, pp.1743-1749.

2. Ebiura T, Echizen T, Ishikava A, Mukai K, Baba T (2004) Selective transesterification of tiolien with methanol to metil oleate and gliserol using alumina loaded with alkali metal salt, Catalyst Today, v.93-95, pp.315-319.

3. Wang Y, Pengrhan SO, Zhanq LZ (2007) Preparation of biodiesel from waste cooking oil via two-step catalyzed process. Energy conversion and Management, v.48, pp.184-188.

4. Arzamendi G, Arquinarene E, Campo J, Zabala S, Gandia IM (2008) "Alkaline and alkalineearth metals compounds as a catalyst for the methanolysis of sunflower oil". //Catalyst Today. 2008. pp.133-135.

5. Kim HJ, Kang MJ, Park YM, Kim OK (2005) Transesterification of vegetable oil to biodiesel using heterogenous base catalyst. Appl.Catalyst, A.v.283, pp.315-320.

6. Ilgen O, Akin AN (2009) Development of alumina.Supported alkaline catalysts used for biodiesel production. Turk.J.Chem., v.33, pp.281-287.

7. Vicente G, Coreton A, Martinez M (1998) Optimization of integrated biodiesel production. J.Azasil.Indus.Crop.Prod., v.8, pp.29-31.

8. Movsumzadeh MM, Ahmedov IM, Mahmudova LR, Aliyev NA, Eyvazova IM (2013) Transesterification of vegetable oils with low molecular weight alcohols in the presence of nano $\mathrm{CaO}$ catalyst. // Neftepererabotka i neftekhimiya. Neftepererabotka i nefteximiya [Oil refining and petrochemistry]. 2013.№12. pp. 39-40

9. (2015) Method of obtaining a catalyst for reaction of transesterification of vegetable oils. The Patent of Azerbaijan Republic İ 20150076
10. Movsumzadeh MM, Ahmedov IM, Mahmudova LR, Aliyev NA, Eyvazova IM (2014) Transesterification of sunflower oil with methyl alcohol in the presence of catalyst.The synthesis of biodiesel fuel. Al'ternativnye istochniki syr'ya i topliva. Sbornik nauchnykh trudov. Minsk. «Belaruskaya navuka» Alternative sources of raw materials and fuel. Collection of scientific papers. Minsk. "Belarusian Science 2014, pp.72-83.

11. Movsumzade MM, Ahmedov IM, Mahmudova LR, Aliyev NA, Imanova XA (2015) The development of fuel based on composition of biodiesel and diesel fuels, improving the exploited properties of diesel engines // Neftepererabotka i nefteximiya [Oil refining and petrochemistry]. 2015. № 9. pp. 40-41.

12. Movsumzadeh MM, Akhmedov IM, Mahmudova LR, Aliyev NA, Quliyeva ZB (2015) The study of cetane number of the compositions on the basis of biodiesel and diesel fuel // Azerbaycan Neft Teserrufati, [Azerbaijan Oil Industry]. 2015. № 2. pp. 44-47

13. (1949) Sintez organicheskikh preparatov.Sintez orqanicheskix preparatov. [The synthesis of organic products] M. 1949, Collection 1, pp. 308-309.

14. Farzaliyev VM, Abbasova MT, Javadova AA, Jafarova IA (2016) International Journal of Research Studies in Science, Engineering and Technology. Vol.3, ISSUE 2016

15. Kanevskaya IQ (1984) Bioloqicheskoe povrejdenie promishlennix materialov. Izdatelstvo Nauka. The biological damage of industrial materials. [Publishing house «Science»] 1984, v.123. 